\title{
Efficacy of sildenafil citrate in women with unexplained recurrent miscarriage preconceptional and during 1 st trimester of pregnancy
}

\section{Original Article}

\author{
Haitham Ahmed Bahaa
}

Department of Obstetrics and Gynecology, Faculty of Medicine, Minia University, Minia

Egypt.

\begin{abstract}
Objective: To evaluate the effect of low dose of sildenafil citrate on females with history of unexplained recurrent miscarriage (RM) before and during 1st trimester of pregnancy.

Patients and Methods: 120 women divided into Group I: Includes 60 patients who received aspirin $75 \mathrm{mg} / \mathrm{day}+\mathrm{folic}$ acid $5 \mathrm{mg}$ / day orally; Group II: Includes 60 patients who received aspirin $75 \mathrm{mg} /$ day+ folic acid $5 \mathrm{mg} /$ day + sildenafil citrate $20 \mathrm{mg} /$ day, orally. The treatment starts from day 1 and continues till the end of the cycle. If menstruation occurred, the treatment is repeated for another 5 cycles or pregnancy occurs. If pregnancy occurred, the treatment continues till 14 weeks of gestation.

Results: Pulsatile index (PI), resistance index (RI) was significantly lower in sildenafil treated women in comparison with sildenafil non treated women. Serum NO level, conception rate and number of cases passed 1st trimester were increased significantly in sildinafil treated group when compared to sildenafil non treated group.

Conclusion: Administration of low dose of sildenafil citrate $(20 \mathrm{mg} /$ day) orally with mild tolerable side effects resulted high possibility of conception and better chance for patients with unexplained RM to maintain their pregnancies in the 1 st trimester.
\end{abstract}

Key Words: Recurrent miscarriage, sildenafil citrate, 1 st trimester.

Received: 01 January 2018, Accepted: 21 January 2018

Corresponding Author: Haitham Ahmed Bahaa, Department of Obstetrics and Gynecology, Faculty of Medicine, Minia University, Minia Egypt, Tel.: 01006808908, E-mail: haitham_bahaa@yahoo.com.

ISSN: 2090-7265, February 2018, Vol.8, No.1

\section{INTRODUCTION}

Recurrent miscarriage (RM) is three or more consecutive miscarriages before the 20th week of gestation, which affects $0.5-1 \%$ of couples ${ }^{[1]}$. The cases of idiopathic recurrent miscarriage are estimated to be $50 \%$ of all abortion cases. In cases of unexplained RM, many modalities of treatment had been suggested e.g. Aspirin ${ }^{[2]}$, prednisolone ${ }^{[3]}$, progesterone ${ }^{[4]}$, metformin ${ }^{[5]}$ and heparin ${ }^{[6]}$.

Endometrial growth seems to be dependent on uterine artery blood flow. The importance of endometrial development on pregnancy outcome has been reported ${ }^{[7]}$. Healthy blood perfusion of the uterus and ovaries may affect the success of assisted reproduction techniques. Nitric oxide (NO) relaxes vascular smooth muscle through cyclic guanosine monophosphate (cGMP). Sildenafil citrate, a type 5-specific phosphodiesterase inhibitor, augments the vasodilator effects of $\mathrm{NO}$ by preventing the degradation of $\mathrm{cGMP}^{[8]}$.
Therefore, how the endometrium quality can improve before pregnancy? This may be a key question in RM patients. Low-dose aspirin and estrogen can improve the endometrium quality ${ }^{[9]}$. Low-dose aspirin $(100 \mathrm{mg})$ significantly improved uterine blood flow velocity, implantation, and pregnancy rate in IVF patients ${ }^{[10]}$.

Studies showed that low dose sildenafil improves uterine artery blood flow, improves endometrial and sub-endometrial vascularity ${ }^{[1]}$. Since its approval by the U.S. Food and Drug Administration in March of 1998, sildenafil citrate has been used for treatment of erectile dysfunction by millions of men. It has not been as effective in women with sexual dysfunction, with the exception of disorders caused by selective serotonin reuptake inhibitors (SSRIs) ${ }^{[12]}$. Low dose sildenafil citrate was used mainly for two indications: implantation failure ${ }^{[11]}$ and $\mathrm{RM}^{[13]}$. Low dose of sildenafil citrate in the form of $20 \mathrm{mg}$ /day orally has tolerable and minor side effects ${ }^{[12]}$.

Our research aimed to evaluate the effect and/or 
benefits of low dose of sildenafil citrate on females with history of unexplained RM before and during 1 st trimester of pregnancy.

\section{PATIENTS AND METHODS}

The present study was carried out in Minia maternity and children university hospital, during the period from 1st of June 2016 until 31st May 2017

Ethical permission was sought from a Local Research Ethics Committee (REC) of the department. The potential benefits and inconveniences of all aspects of the study were clearly stated in the ethical application forms to the corresponding committee to access the fills and dealing anonymously with the retrieved data.

\section{Participants}

Randomized sample consists of 120 patients suffering of recurrent miscarriage at 1 st trimester without definite cause who attend to infertility outpatient clinic in Minia maternity and children university hospital.

\section{Inclusion criteria}

Age: 20 - 35 years old; patient has history of 3 or more 1st trimester abortion; regular cycles with good ovulation; normal hormonal profile ( FSH , LH , Prolactin); normal hystroscopic examination or at least normal hystrosalpigogram (HSG); patient is free of any chronic disorders or Anti-phospholipid syndrome (APS).

\section{Exclusion criteria}

Age: less than 20 or more than 35 years old; presence of any uterine malformation e.g. fibroids, polyps, bicornuate or septate uterus; presence of polycystic ovaries (PCO) or endometriosis; abnormal karyotyping; presence of uncontrolled D.M. or renal or hepatic or cardiac or thyroid impairment or already diagnosed as APS. 120 patients are divided into 2 groups:

- Group I: Includes 60 patients, patients received aspirin 75 $\mathrm{mg}$ / day oral tablet \& folic acid $5 \mathrm{mg}$ / day oral tablet.

- Group II: Includes 60 patients, patients received aspirin $75 \mathrm{mg}$ / day oral tablet and folic acid $5 \mathrm{mg}$ / day oral tablet in addition to sildenafil citrate $20 \mathrm{mg} /$ day oral tablet. The treatment starts from day 1 and continues till the end of the cycle. If menstruation occurred, the treatment is repeated for another 5 cycles or pregnancy occurs. If pregnancy occurred (evidenced by B-HCG titre), the treatment continues till 14 weeks of gestation.

\section{The Plan}

In both groups, pregnancy is allowed to occur spontaneously without induction of ovulation or using IVF methods, only intervention occurred is just advising the patients about the best time for intercourse during the fertile period. If pregnancy occurred (evidenced by B-HCG titre
1 week after missed period), transvaginal U/S scan is done to detect intra-uterine gestational sac (IUGS) 1 week later.

Another scan occurs 2 weeks later to detect and confirm presence of fetal pole and cardiac pulsation. At 10th week of gestation, another scan with doppler is done to assess uterine artery pulsatile index (PI), resistance index (RI). Weekly U/S is done till reaching 14 weeks of gestation. Serum NO level is measured at 10th week of gestation.

If fetal death (became missed abortion) occurred at any time, all medications stop and referral of the patient to obstetric department to start and choose suitable method for induction of abortion.

\section{Statistical analysis}

The collected data were organized, tabulated and statistically analyzed using SPSS software computer package (Statistical Package for Social Science) version 20 (SPSS Inc, USA).

\section{RESULTS}

Table (1) presented the results of Doppler ultarsonography between groups, the results showed that the mean of PI was significantly $(\mathrm{P} \leq 0.01)$ lower in Group II as compared to group I. Also, the same trend of result was found in RI, the mean of RI was significantly $(\mathrm{P} \leq 0.01)$ lower in group II as compared to group I.

Table 1: Pulsatility index and Resistive index between groups.

\begin{tabular}{llllll}
\hline \multicolumn{5}{c}{ Groups } \\
Variables & \multicolumn{2}{c}{$\begin{array}{l}\text { Group I } \\
(\mathrm{n}=60)\end{array}$} & \multicolumn{2}{c}{$\begin{array}{c}\text { Group II } \\
(\mathrm{n}=60)\end{array}$} & $\begin{array}{c}p \text {. value } \\
(\text { sig. })\end{array}$ \\
& $\mathrm{M}$ & $\mathrm{SD}$ & $\mathrm{M}$ & $\mathrm{SD}$ & \\
PI & 1.85 & 0.13 & 0.78 & 0.12 & $<0.001 * *$ \\
RI & 0.79 & 0.13 & 0.58 & 0.09 & $<0.001 * *$ \\
\hline
\end{tabular}

Independent sample T-test was used.

** Significant difference at $p$. value $(p \leq 0.01)$.

$[($ Pulsatility index $=\mathrm{PI})$; (Resistive index $=\mathrm{RI})]$.

The serum level of NO was significantly $(\mathrm{P} \leq 0.01)$ higher in group II compared to group I (Table 2).

Table 2: Serum nitric oxide level at 10th week of gestation between groups.

\begin{tabular}{lccccc}
\hline \multicolumn{7}{c}{ Groups } \\
\hline Variables & \multicolumn{2}{c}{$\begin{array}{c}\text { Group I } \\
(\mathrm{n}=60)\end{array}$} & \multicolumn{2}{c}{$\begin{array}{c}\text { Group II } \\
(\mathrm{n}=60)\end{array}$} & $\begin{array}{c}p \text {. value } \\
(\text { sig. })\end{array}$ \\
& $\mathrm{M}$ & $\mathrm{SD}$ & $\mathrm{M}$ & $\mathrm{SD}$ & \\
$\begin{array}{l}\text { serum NO } \\
(\mu \mathrm{mol} / \mathrm{L})\end{array}$ & 409.5 & 26.6 & 623.2 & 24.4 & $<0.001^{* *}$ \\
\hline
\end{tabular}

Independent sample T-test was used.

** Significant difference at $p$. value $(p \leq 0.01)$.

[Nitric oxide $=\mathrm{NO}]$. 
Figure 1 showed that group II had significantly higher conception rate compared to group I.

Our results showed the outcome (Passing 1 st trimester) between groups, that revealed the number of cases passed 1st trimester in group II were significantly $(p \leq 0.05)$ higher compared to group I (Figure 2).
Results of Socioeconomic level between groups (Table 3) revealed that there was no significant difference between groups.

Regarding, consanguinity degree between groups, there was no significant difference was found between groups in consanguinity degree (Figure 3 ).

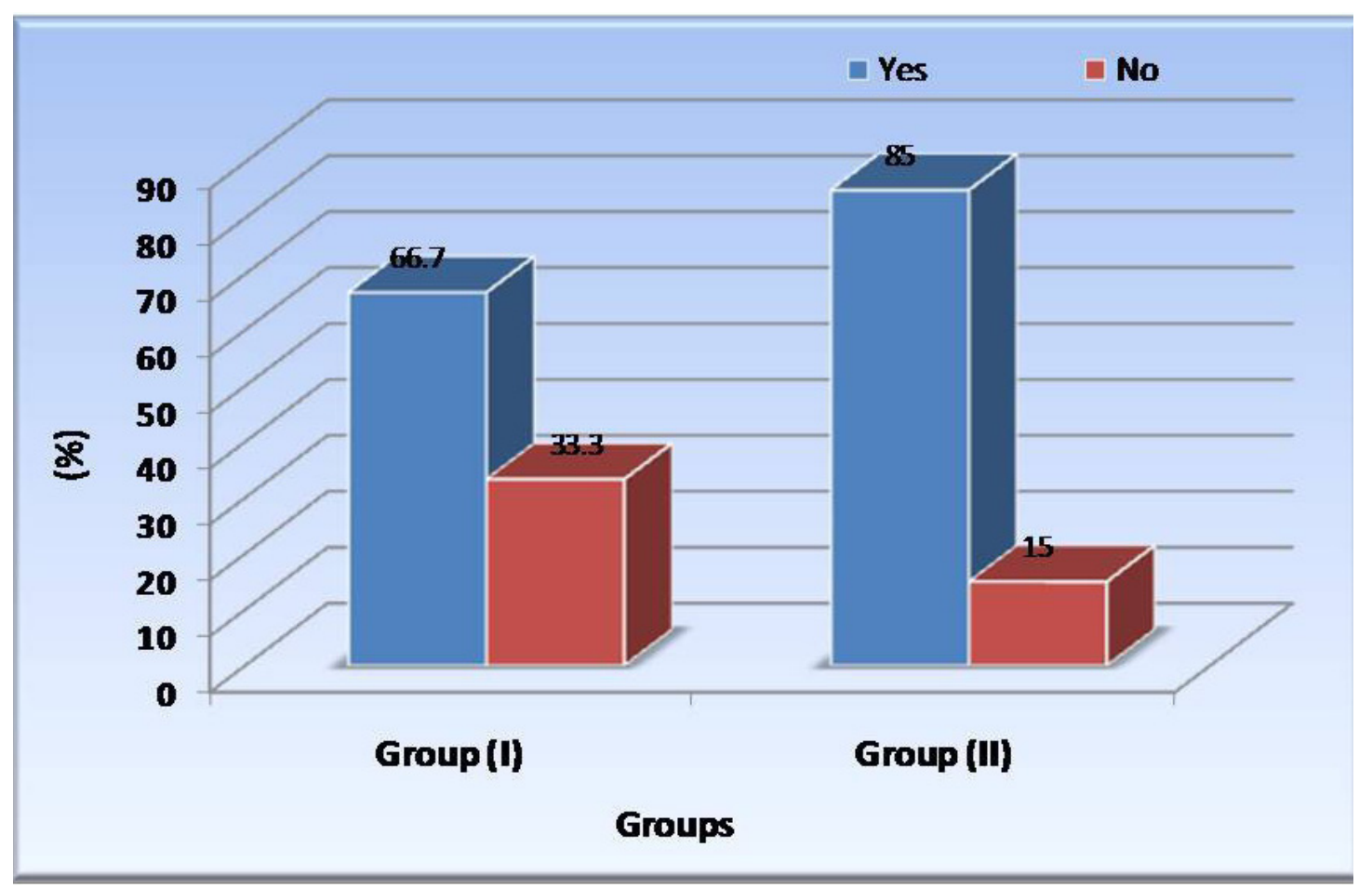

Fig. 1: Conception rate between groups.

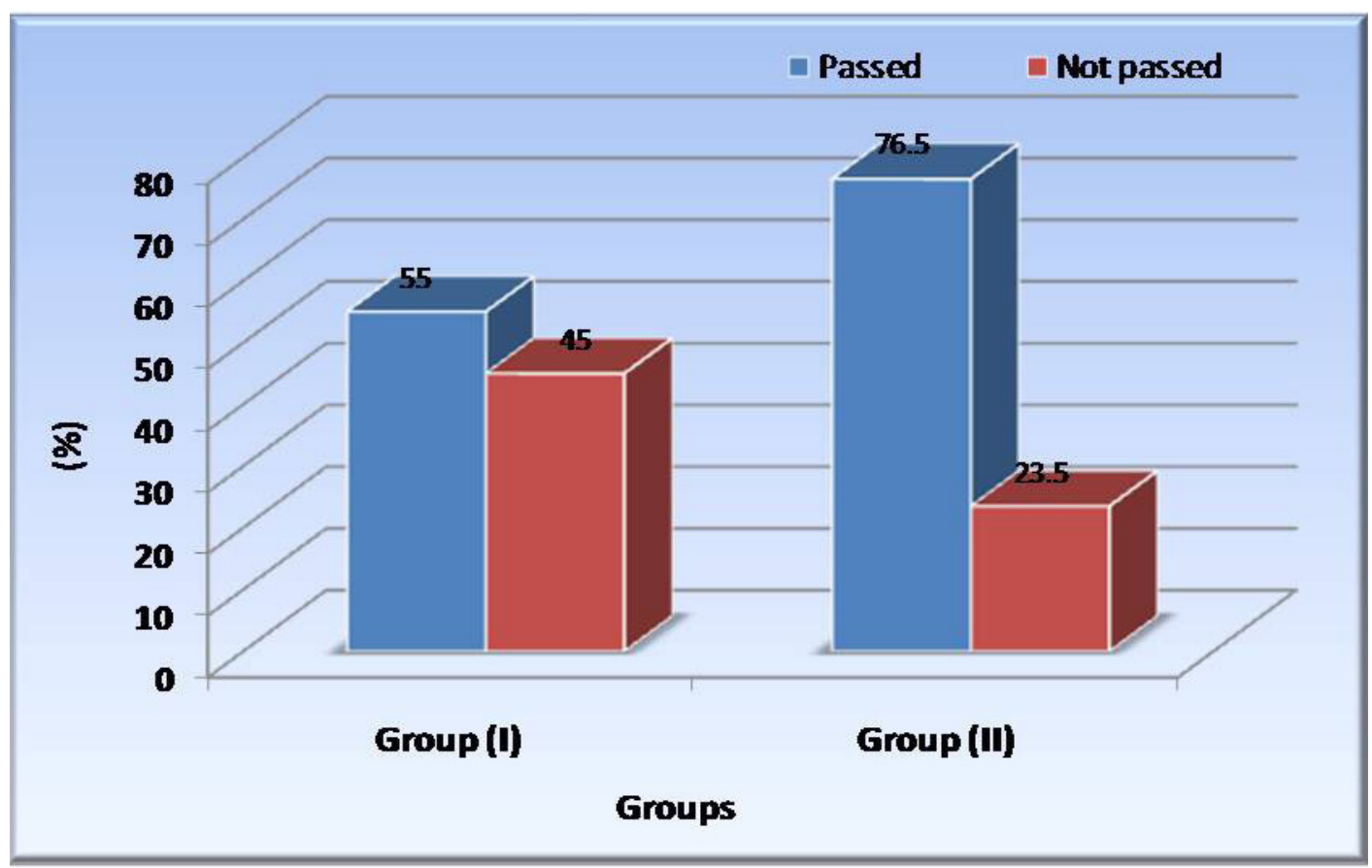

Fig. 2: Outcome (Passing 1st trimester) between groups. 
Table 3: Socioeconomic level between groups

\begin{tabular}{|c|c|c|c|c|c|c|}
\hline \multicolumn{7}{|c|}{ Groups } \\
\hline \multirow{3}{*}{ Variables } & \multicolumn{2}{|c|}{ Group (II) } & \multicolumn{4}{|c|}{ Group (I) } \\
\hline & & & & \multicolumn{2}{|c|}{$(n=60)$} & $\begin{array}{l}P . \text { value } \\
\quad \text { (sig.) }\end{array}$ \\
\hline & & No. & $\%$ & No. & $\%$ & \\
\hline \multirow{3}{*}{$\begin{array}{l}\text { Socioeconomic } \\
\text { level }\end{array}$} & Low & 29 & 48.4 & 25 & 41.6 & \multirow{3}{*}{$0.36^{\mathrm{NS}}$} \\
\hline & Moderate & 23 & 38.3 & 21 & 35.0 & \\
\hline & High & 8 & 14.3 & 14 & 23.3 & \\
\hline
\end{tabular}

Chi square test was used.

[Not significant $=\mathrm{NO}$.

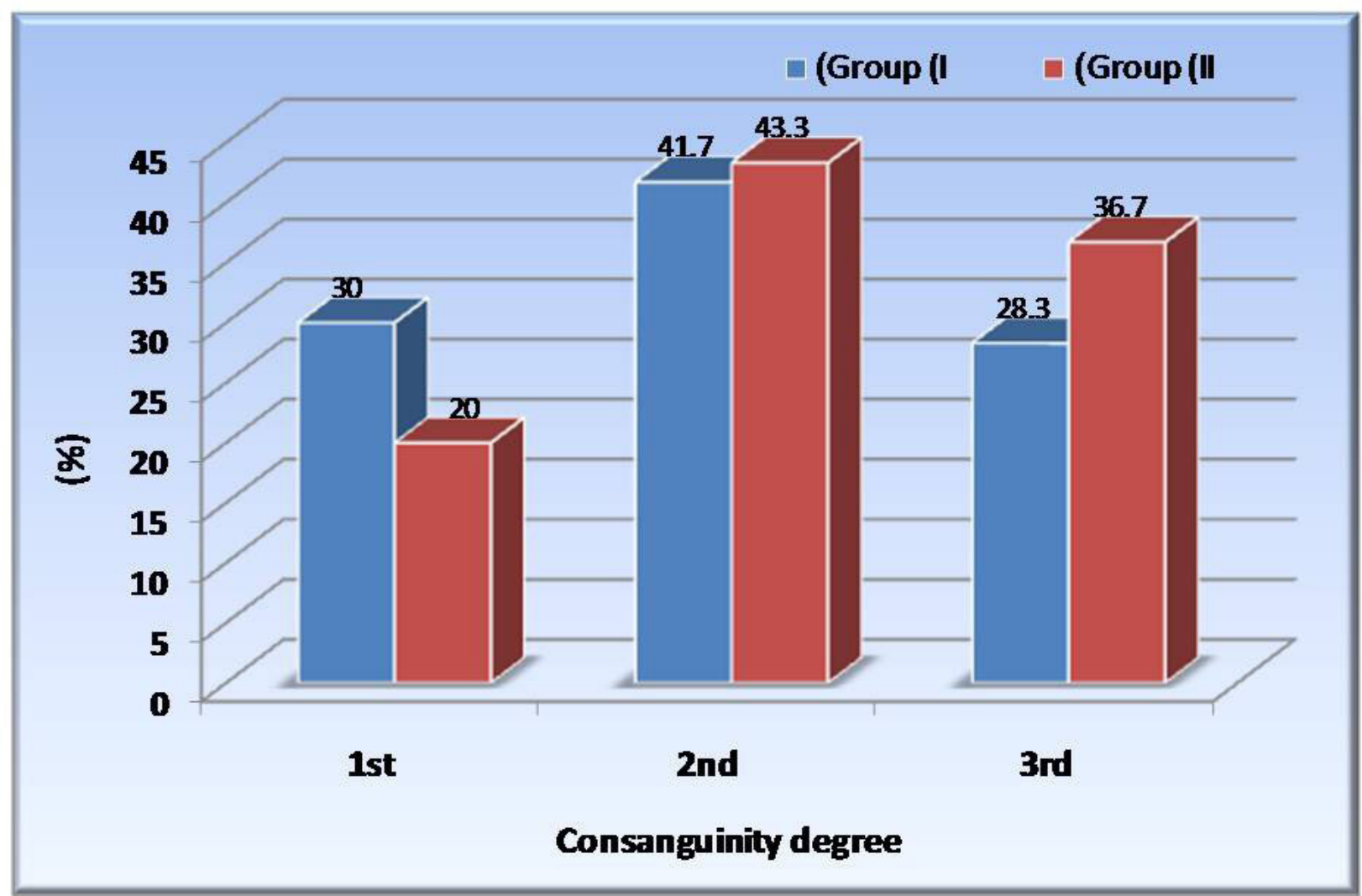

Fig. 3: Consanguinity degree between groups. 


\section{DISCUSSION}

Recurrent miscarriage is the loss of more than two consecutive pregnancies before the 20th week of gestation $^{[13]}$. It is either primary (women without previous live born infant) or secondary (woman with at least one prior live born infant $)^{[14]}$.

Sildenafilcitrateinhibitstheactivityofphosphodiesterase type 5 (PDE5), thus preventing degradation of cGMP and augments the vasodilatory effects of NO. PDE5 is found in the corpus cavemosum, the erectile tissue of the penis and it is also found in the retina and vascular endothelium. Sildenafil citrate is a specific inhibitor of PDE5 $5^{[15,16]}$.

Also, it was reported that sildenafil citrate rapidly reduces mean arterial pressure while simultaneously increases heart rate and blood flow to the uterus ${ }^{[17]}$. Furthermore, sildenafil influences angiogenesis, platelet activation, proliferation of regulatory $\mathrm{T}$ cells, and production of proinflammatory cytokines and autoantibodies ${ }^{[18]}$.

The present results revealed that PI and RI were significantly decreased in group II compared to group I. These results were in agreement with $\operatorname{Amin}^{[19]}$ who found that Sildenafil Citrate group had significantly lower Pulsatility index compared to Placebo group and the values of PI in his study (1.98 in Placebo group and 0.78 in Sildenafil group) were almost similar to our obtained values. Also, Amin ${ }^{[19]}$ found that Sildenafil Citrate treated group of patients had significantly lower Resistive index than Placebo group and also his obtained values of PI were comparable with ours $(0.75$ in Placebo group and 0.51 in sildenafil group). They concluded that, sildenafil citrate has an effective role in increasing the uterine arteries blood flow in patients with recurrent miscarriage.

Also, Mostafa ${ }^{[16]}$ found that patients who received sildenafil citrate had significantly lower Pulsatility index, Resistive index and Systolic/diastolic ratio compared to Placebo group. He added that sildenafil citrate has an effective role in increasing the uterine arteries blood flow in patients with recurrent miscarriage. In our study, the results demonstrated that serum NO level was significantly $(p \leq 0.01)$ higher in group II compared to group I. These results are in accordance with those of Amin $^{[19]}$ and Mostafa ${ }^{[16]}$. This result was expected because sidenafil citrate is $\mathrm{NO}$ donor and consequently increases serum NO of treated group, thus may explain the increase in uterine blood flow.

$\mathrm{NO}$ is a key signaling molecule involved in the vasodilatory response of smooth muscle cells. NO activates cGMP protein kinase G (PKG) pathway within smooth muscle cells to promote smooth muscle cell relaxation. Animal studies were among the first to identify NO as a vasodilatory agent that increased uterine blood flow ${ }^{[20]}$.

Also, it was reported that sildenafil citrate inhibits phosphodiesterase 5 (PDE5), maintains the activation of cGMP and PKG and maximizes the effect of existing NO thus facilitating smooth muscle cell relaxation. The potent vasodilatory action of sildenafil has led researchers to evaluate sildenafil as a treatment in assisted reproduction where low uterine blood flow is perceived to be a contributor to implantation failure ${ }^{[21]}$. Also, constant and smooth blood flow in the uterine arteries can be achieved by the administration of drugs, which increases the level of $\mathrm{NO}^{[15]}$. Furthermore, with the use of sildenafil, cGMP remains elevated, which leads to vascular relaxation and increased blood flow to the endometrium ${ }^{[22]}$.

In our study, the present results showed that sildenafil treated group had significantly higher conception rate as compared to group I. These finding of increased conception rate and enhanced chance of successful pregnancy in women with a history of RM by administration of sildenafil citrate were reported by many studies ${ }^{[13,15,23,24]}$.

Successful implantation requires good embryo quality, appropriately timed and arranged endometrial receptivity and efficient crosstalk between the embryo and the receptive endometrium. It is thought that the impairment of any one of these factors or biological processes may result in implantation failure ${ }^{[25]}$.

One of the possible explanation of this result is that sildenafil citrate decreased natural killer cell activity and enhanced the chance of successful pregnancy and endometrial thickness was significantly increased after such therapy in women with a history of RM as it was reported by Jerzak et $a l^{[24]}$ and also, they concluded that vaginal sildenafil might be an interesting therapeutic option before conception in women with histories of reproductive failure. In addition, it was reported that sildenafil improved the measured antioxidants concentrations [total antioxidant capacity (TAC), glutathione S-transferase (GSH-S-T) and catalase (CAT), superoxide dismutase (SOD)] and improved oxidative stress by reducing malondialdehyde (MDA $)^{[13]}$. They also concluded that intravaginal sildenafil citrate tablets used as suppositories might be a novel, interesting, safe antiabortive option in the treatment of threatened miscarriage in patients.

Our study revealed that the outcome was significantly improved in sildenafil group. Similar findings were obtained by $\mathrm{Amin}^{[19]}$ who found that the abortion rate was significantly less in patients who recieved sildenafil. Similar results were obtained by El-far and his coworkers ${ }^{[26]}$ and Mostafa ${ }^{[16]}$. These results may be explained by that sildenafil improved uterine blood flow and significantly improves endometrial thickness which consequently improves implantation.

Successful pregnancy requires adequate growth of the endometrium to support the ovum implantation during menstrual cycle. Endometrial thickness (EM) is one of the strongest predictors of implantation rate and ongoing pregnancy success rate. Some reports discussed the possible beneficial effects of sildenafil citrate on EM. It leads to smooth muscle relaxation and vasodilation, it is a potential candidate for female infertility, especially in 
the management of thin endometrium, which leads to low implantation and pregnancy rates ${ }^{[17]}$. Many studies showed improved uterine artery blood flow and endometrial thickness after the use of low dose vaginal sildenafil ${ }^{11,24]}$. Based on the results of our study, we may recommend the use of low dose oral sildenafil for cases with a history of idiopathic RM before and during 1 st trimester of pregnancy.

\section{CONCLUSION}

Administration of low dose of sildenafil citrate $(20 \mathrm{mg} /$ day $)$ orally with mild tolerable side effects resulted in healthy blood perfusion for uterus and ovaries through increase NO level with its vasodilator effect. Furthermore, NO increase the endometrial receptivity which leads to high possibility of conception and better chance for patients with unexplained RM to maintain their pregnancies in the 1 st trimester.

\section{CONFLICT OF INTEREST}

There are no conflicts of interest.

\section{REFERENCES}

1. Klock SC. Psychological adjustment to twins after infertility. Best Pract Res Clin Obstet Gynaecol.2004;18(4): 645-656. [PubMed].

2. Rai R, Backos M, Baxter N, Chilcott I, Regan L. Recurrent miscarriage--an aspirin a day? Hum Reprod. 2000; 15(10): 2220-3

3. Quenby S, Kalumbi C, Bates M, Farquharson R, Vince G. 2005. Prednisolone reduces preconceptual endometrial natural killer cells in women with recurrent miscarriage. Fertility and Sterility 84: 980-984

4. Oates-Whitehead RM, Baumer JH, Haines L, Love S, Maconochie I K, Gupt, A, Flynn I. Intravenous immunoglobulin for the treatment of Kawasaki disease in children. The Cochrane Library 2003.

5. Glueck CJ, Wang P, Goldenberg N, SieveSmith L. Pregnancy outcomes among women with polycystic ovary syndrome treated with metformin. Human Reproduction 2002; 17(11), 2858-2864.

6. Niers TM, Klerk CP, DiNisio M. Mechanisms of heparin induced anti-cancer activity in experimental cancer models. Crit Rev Oncol Hematol 2007; 61: 195-207.
7. King K, Smith S, Chapman M, Sacks G. Detailed analysis of peripheral blood natural killer (NK) cells in women with recurrent miscarriage. Human Reproduction 2010; 25: 52-58.

8. Paulus WE, Strehler E, Zhang M, Jelinkova L, El-Danasouri I, Sterzik K. Benefit of vaginal sildenafil citrate in assisted reproduction therapy. Fertil Steril. 2002; 77: 846-847.

9. Weckstein LN, Jacobson A, Galen D, Hampton K, Hammel J. Low-dose aspirin for oocyte donation recipients with a thin endometrium: prospective, randomized study. Fertility and sterility 1997; 68(5): 927-930.

10. Rubinstein M, Marazzi A, Polak de Fried E. Low-dose aspirin treatment improves ovarian responsiveness, uterine and ovarian blood flow velocity, implantation and pregnancy rates in patients undergoing in vitro fertilization: a prospective, randomized, double-blind placebocontrolled study, Fertil Steril 1999; 71: 825-829.

11. Sher G, Fisch JD. Vaginal sildenafil (Viagra): a preliminary report of a novel method to improve uterine artery blood flow and endometrial development in patients undergoing IVF .Human Reproduction 2000; 15(4): 806-809.

12. Boyce EG, Umland EM. Sildenafil citrate: a therapeutic update. Clinical therapeutics 2001; 23(1): 2-23.

13. El-Far M1, El-Motwally AG, Hashem IA, Bakry N. Biochemical role of intravaginal sildenafil citrate as a novel antiabortive agent in unexplained recurrent spontaneous miscarriage: first clinical study of four case reports from Egypt. Clin Chem Lab Med 2009; 47(11): 1433-8.

14. Ford HB, Schust DJ. Recurrent pregnancy loss: etiology, diagnosis, and therapy. Reviews in obstetrics and gynecology 2009; 2(2): 76.

15. Ohams M, Jerzak M, Gorski A. Effects of sildenafil citrate and etanercept treatment on TNFlevels in peripheral blood of women with recurren miscarriage. Ginekol Pol 2015; 86: 520-524.

16. Mostafa T. Useful Implications of Low-dose Longterm Use of PDE-5 Inhibitors. Sexual Medicine Reveiws 2016; 4(3): 270-284.

17. Benni JM, Patil PA. Non-diabetic clinical 
applications of insulin. Journal of basic and clinical physiology and pharmacology 2016; 27(5): 445-456.

18. Kniotek M, Boguska A. Sildenafil Can Affect Innate and Adaptive Immune System in Both Experimental Animals and Patients. Journal of immunology research 2017; ID 4541958.

19. Amin RAA, Assaf AM, Al Berrri SA, Al Nori MA. Effect of sildenafil citrate in women of reccrunt miscarriage, thesis Benha University. $2011 ; 11223466$.

20. Ozaki K, Spolski R, Feng CG, Qi CF, Cheng J, Sher A, et al. A critical role for IL-21 in regulating immunoglobulin production. Science 2002; 298(5598): 1630-1634

21. Hale SA, Jones CW, Osol G, Schonberg A, Badger GJ, Bernstein IM. Sildenafil increases uterine blood flow in nonpregnant nulliparous women. Reprod Sci 2010; 17 (4): 358-365.

22. Firouzabadi R D , Davar R, Hojjat F, Mahdavi M. Effect of sildenafil citrate on endometrial preparation and outcome of frozen-thawed embryo transfer cycles: a randomized clinical trial. Iran J Reprod Med 2013; 11(2): 151-158.

23. Zinger M, Liu JH, Thomas MA. Successful use of vaginal sildena? citrate in two infertility patients with Asherman's syndrome. J Women's Health 2006; 15 (4): 442-444.

24. Jerzak M, Kniotek M, Mrozek J. Sildenafil citrate decreased natural killer cell activity and enhanced chance of successful pregnancy in women with history of recurrent miscarriage. Fertil Steril 2008; 90 (5):1848-1853.

25. Maruyama T. Therapeutic Strategies for Implantation Failure due to Endometrial Dysfunction. J Mammal Ova Res 2009; 26: 129-133.

26. El-Far M, El-Sayed IH, El-Motwally AEG, Hashem IA, Bakry N. Tumor necrosis factor- $\alpha$ and oxidant status are essential participating factors in unexplained recurrent spontaneous abortions. Clinical Chemical Laboratory Medicine 2007; 45(7): 879-883. 